\title{
Co-implantation of Tumor and Extensive Surrounding Tissue Improved the Establishment Rate of Surgical Specimens of Human-Patient Cancer in Nude Mice: Toward the Goal of Universal Individualized Cancer Therapy
}

\author{
TAKUYA MURATA ${ }^{1}$, CHIHIRO HOZUMI ${ }^{2}$, YUKIHIKO HIROSHIMA ${ }^{3}$, KOICHIRO SHIMOYA $^{4}$, \\ ATSUSHI HONGO ${ }^{1}$, SACHIKO INUBUSHI $^{5}$, HIROKAZU TANINO ${ }^{5}$ and ROBERT M. HOFFMAN ${ }^{6,7}$ \\ ${ }^{1}$ Department of Obstetrics and Gynecology 2, Kawasaki Medical School, Okayama, Japan; \\ ${ }^{2}$ AntiCancer Japan Inc, Narita, Japan; \\ ${ }^{3}$ Department of Cancer Genome Medicine, Kanagawa Cancer Center Research Institute, Kanagawa, Japan; \\ ${ }^{4}$ Department of Obstetrics and Gynecology 1, Kawasaki Medical School, Kurashiki, Japan; \\ ${ }^{5}$ Breast Surgery, Department of Surgery, Kobe University Graduate School of Medicine, Kobe, Japan; \\ ${ }^{6}$ AntiCancer Inc, San Diego, CA, U.S.A.; \\ ${ }^{7}$ Department of Surgery, University of California, San Diego, CA, U.S.A.
}

\begin{abstract}
Background/Aim: The discovery of the nude mouse model enabled the experimental growth of humanpatient tumors. However, the low establishment rate of tumors in nude and other immunodeficient strains of mice has limited wide-spread clinical use. Materials and Methods: In order to increase the establishment rate of surgical specimens of patient tumors, we transplanted tumors to nude mice subcutaneously along with large amounts of surrounding tissue of the tumor. Results: The new transplantation method increased the establishment rate in nude mice to $66 \%$ compared to the old method of implanting the surgical tumor specimen with surrounding tissue removed (14\%). High stage and presence of metastasis in the patient donor are positively correlated to tumor engraftment in nude mice. Conclusion: The new method can potentially
\end{abstract}

This article is freely accessible online.

Correspondence to: Takuya Murata, Ph.D., MD, Associate Professor of Obstetrics and Gynecology 2, Kawasaki Medical School, 2-6-1 Nakasange, Kita-ku, Okayama 700-8505, Japan. Tel: +81 862252111, Fax: +81 862328343, e-mail: t-muratactac@gmail.com and Robert M. Hoffman, Ph.D., Professor of Surgery, University of California, AntiCancer, Inc., 7917 Ostrow Street, San Diego, CA 92111, U.S.A. Tel: +1 8586542555, Fax: +1 8582684175, e-mail: all@anticancer.com

Key Words: Patient-derived xenograft, PDX, patient-derived orthotopic xenograft (PDOX), nude mice, tumor implantation, surrounding tissue, co-implantation, take rate, individualized medicine, gynecological cancer, breast cancer. allow most cancer patients who undergo surgery or biopsy to have their own mouse model for drug-sensitivity testing.

Cancer-drug sensitivity depends on the individual characteristics of the patient's tumor. Therefore, cancer chemotherapy needs to be individualized $(1,2)$. Rygaard was the first to successfully transplant and grow surgical cancer specimens in nude mice in 1969 (3). The surgical specimens were transplanted subcutaneously in the nude mice. Laboratories in the United States, Europe, China and Japan adopted this method and it is in use today under the term patient-derived xenograft (PDX) (4). However, since the time of Rygaard, there has not been a significant increase in the establishment frequency of human tumors in nude and other immune-deficient mice, which has inhibited the use of PDX models for individualized cancer therapy. The standard implantation technique is to first remove the surrounding tissue from the surgical cancer specimen. In the present report we describe a novel approach of co-implanting the tumor along with large amounts of surrounding tissue into a pocket made in the subcutaneous space of nude mice. The new method greatly increased the establishment frequency of patient tumors in nude mice, that should enable its widespread clinical use.

\section{Materials and Methods}

Athymic nude mice (AntiCancer Japan Inc, Narita, Japan) were used for tumor implantation. All procedures followed ethical procedures for use of experimental animals. All patients provided written informed consent for implantation of their tumors in nude 

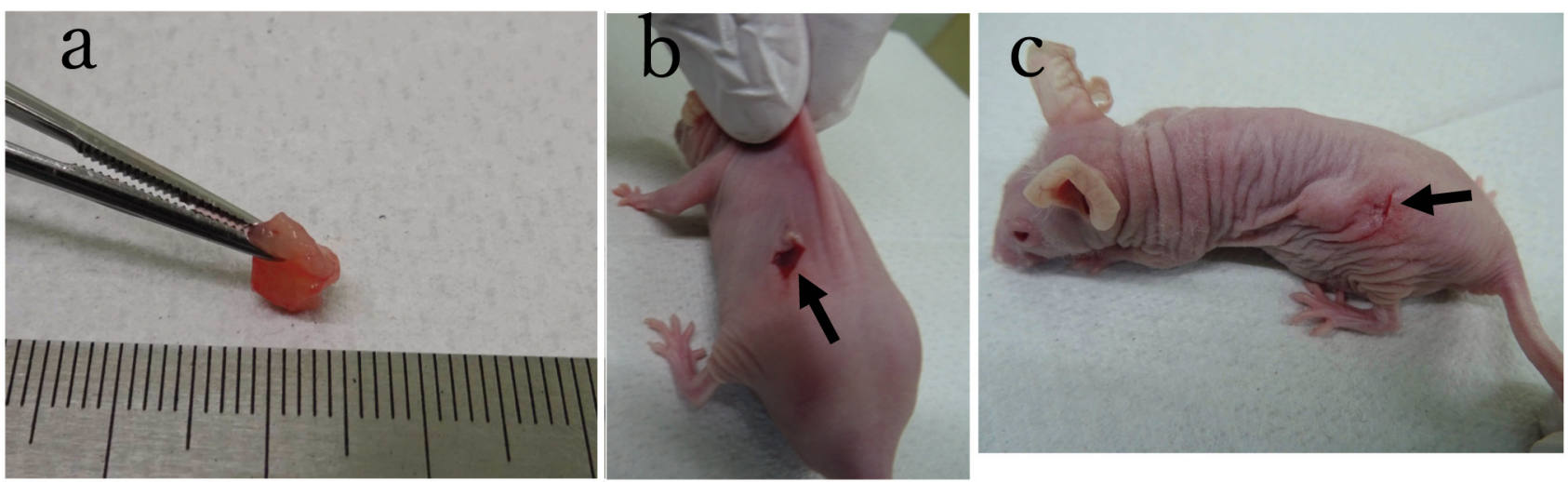

Figure 1. Method of co-transplantation of tumor and surrounding tissue. (a) Representative patient-derived tumor specimen with a large amount of surrounding tissue. (b) Tumor specimen and surrounding tissue were inserted into a pocket in the subcutaneous space through an incision indicated by arrow. (c) Immediately after tumor and surrounding tissue were inserted in the subcutaneous pocket.

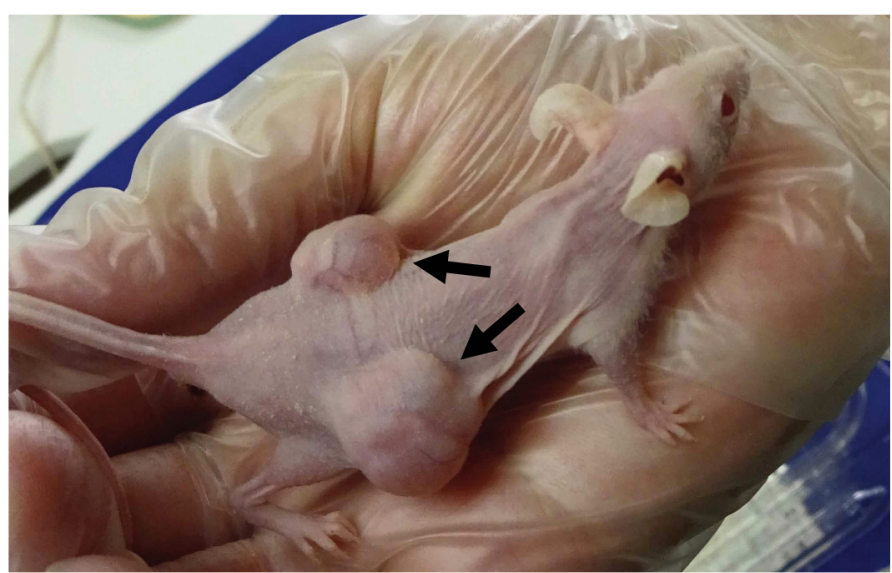

Figure 2. Representative growing patient-derived tumor co-transplanted with extensive surrounding tissue, four weeks after engraftment was performed. Arrows show the growing tumor.

mice under the Institutional Review Board approval of Kawasaki Medical School, Kurashiki, Japan. Tumors collected at surgery were placed in DMEM at $4^{\circ} \mathrm{C}$ and cooled on ice until transplantation at the AntiCancer Japan Laboratories.

Subcutaneous transplantation of patient tumors was performed in the back-skin of nude mice under anesthesia. A skin incision of approximately $1 \mathrm{~cm}$ was made and the tumors and surrounding tissue derived from the patient were inserted into a deep pocket formed by the incision in the subcutaneous space. As a comparison some tumors were transplanted in which the surrounding tissue was removed as much as possible, so that only the tumor was transplanted.

The transplanted tumors were observed for 12 weeks or longer to confirm engraftment.

\section{Results}

The method of tumor co-implantation along with extensive surrounding tissues is shown in Figure 1.
From 2015 to the present, tumor implantation in nude mice was performed for 43 cases, including 41 cases of gynecologic malignancy and 2 cases of breast cancer. Table I shows the characteristics of the patients.

The engraftment success rate improved to $66 \%(p=0.02)$ by co-transplanting tumors with surrounding tissues compared to transplanting the tumor only (14\%) (Table II). Figure 2 shows a representative growing tumor that was originally co-transplanted with surrounding tissues. Multivariate logistic regression analysis showed that high stage and metastasis in the patient are positively related to the success of engraftment ( $p=0.006$ and $p=0.009$ respectively).

\section{Discussion}

Individualized cancer therapy currently uses genome analysis (5), drug-sensitivity testing with 3-D culture of tumor 
Table I. Patient characteristics.

\begin{tabular}{|c|c|c|c|c|c|c|}
\hline Tumor origin & Histology & Primary/Recurrence & Stage & Metastasis & Age & Neoadjuvant chemotherapy \\
\hline Ovary & Granulosa cell tumor & Recurrence & High & - & 69 & + \\
\hline Cervix & Squamous cell carcinoma & Primary & High & + & 28 & - \\
\hline Corpus & Endometrioid & Primary & Low & - & 45 & - \\
\hline Cervix & Squamous cell carcinoma & Primary & High & + & 46 & - \\
\hline Cervix & Squamous cell carcinoma & Primary & Low & - & 57 & - \\
\hline Cervix & Squamous cell carcinoma & Recurrence & High & + & 46 & + \\
\hline Fallopian tube & Serous & Primary & High & - & 58 & - \\
\hline Cervix & Squamous cell carcinoma & Primary & Low & - & 33 & - \\
\hline Fallopian tube & Serous & Primary & Low & - & 62 & - \\
\hline Cervix & Squamous cell carcinoma & Primary & Low & - & 43 & - \\
\hline Ovary & Endometrioid & Primary & Low & - & 60 & - \\
\hline Ovary & Mucinous & Primary & High & - & 76 & - \\
\hline Ovary & Clear & Primary & High & + & 63 & - \\
\hline Breast & Matrix cell tumor & Primary & High & + & 40 & - \\
\hline Ovary & Poorly differentiated carcinoma & Primary & High & + & 42 & - \\
\hline Ovary & Clear & Primary & Low & - & 76 & - \\
\hline Ovary & Carcinosarcoma & Primary & High & - & 79 & - \\
\hline Corpus & Endometrioid & Primary & Low & - & 45 & - \\
\hline Cervix & Squamous cell carcinoma & Primary & High & + & 51 & - \\
\hline Corpus & Serous & Primary & High & + & 64 & - \\
\hline Ovary & Clear & Primary & Low & - & 47 & - \\
\hline Corpus & Neuroendocrine & Primary & High & - & 52 & - \\
\hline Cervix & Squamous cell carcinoma & Primary & Low & - & 40 & - \\
\hline Corpus & Endometrioid & Primary & High & - & 70 & - \\
\hline Cervix & Clear & Primary & High & + & 74 & - \\
\hline Corpus & Endometrioid & Recurrence & High & + & 50 & - \\
\hline Corpus & Endometrioid & Primary & Low & - & 80 & - \\
\hline Corpus & Endometrioid & Primary & High & + & 67 & - \\
\hline Cervix & Squamous cell carcinoma & Primary & Low & - & 66 & - \\
\hline Corpus & Endometrioid & Primary & Low & - & 47 & - \\
\hline Corpus & Mixed type(Serous/Clear) & Primary & High & + & 71 & - \\
\hline Corpus & Serous & Primary & High & + & 73 & - \\
\hline Cervix & Squamous cell carcinoma & Primary & High & - & 55 & - \\
\hline Corpus & Endometrioid & Primary & Low & - & 59 & - \\
\hline Ovary & Serous & Primary & High & + & 64 & - \\
\hline Corpus & Serous & Recurrence & High & + & 66 & - \\
\hline Corpus & Carcinosarcoma & Primary & High & + & 69 & - \\
\hline Breast & Matrix cell tumor & Recurrence & High & + & 43 & + \\
\hline Cervix & Adenocarcinoma & Primary & High & + & 51 & - \\
\hline Ovary & Carcinosarcoma & Recurrence & High & + & 69 & - \\
\hline Ovary & Endometrioid & Primary & High & + & 38 & + \\
\hline Ovary & Serous & Primary & High & + & 61 & - \\
\hline Corpus & Leiomyosarcoma & Primary & High & _- & 53 & _- \\
\hline
\end{tabular}

High stage: tumor is stage 3 or 4 . Low stage: tumor is stage 1 or 2 .

fragments $(6-9)$ or organoids $(10,11)$ as well as patientderived xenograft (PDX) or, patient-derived orthotopic xenograft (PDOX) models (12-16). Genome analysis has helped only a limited number of cancer patients identify effective drugs (17). PDX and PDOX models for patient testing have been limited due to low take rates of patient tumors in nude and other immune-deficient mice and are therefore not widely used for individualized patient therapy.

Therefore, it is important to increase the success rate of patient-tumor establishment in nude or other immune- deficient mice in order to increase their clinical use. In the present study we have shown surrounding tissue cotransplanted with the tumor greatly increases the establishment rate of patient tumors in nude mice. This development should make PDX and PDOX models widely available for cancer patients in the future for individualized cancer therapy.

The potential disadvantage of the co-implantation method is for small tumor specimens, such as from a core-needle biopsy, in which surrounding tissue may not be available. 
Table II. Comparison of establishment of tumors in nude mice by implanting tumor vs. implanting tumor + surrounding tissue. Method 1: Tumor implanted without surrounding tissue. Method 2: Tumor implanted with surrounding tissue.

\begin{tabular}{|c|c|c|}
\hline Case number & Method & Tumor take \\
\hline 1 & 1 & - \\
\hline 2 & 1 & - \\
\hline 3 & 1 & - \\
\hline 4 & 1 & - \\
\hline 5 & 1 & + \\
\hline 6 & 1 & - \\
\hline 7 & 1 & - \\
\hline 8 & 2 & + \\
\hline 9 & 2 & - \\
\hline 10 & 2 & - \\
\hline 11 & 2 & - \\
\hline 12 & 2 & + \\
\hline 13 & 2 & + \\
\hline 14 & 2 & + \\
\hline 15 & 2 & + \\
\hline 16 & 2 & - \\
\hline 17 & 2 & + \\
\hline 18 & 2 & - \\
\hline 19 & 2 & - \\
\hline 20 & 2 & - \\
\hline 21 & 2 & + \\
\hline 22 & 2 & + \\
\hline 23 & 2 & + \\
\hline 24 & 2 & + \\
\hline 25 & 2 & + \\
\hline 26 & 2 & + \\
\hline 27 & 2 & - \\
\hline 28 & 2 & + \\
\hline 29 & 2 & - \\
\hline 30 & 2 & - \\
\hline 31 & 2 & + \\
\hline 32 & 2 & + \\
\hline 33 & 2 & + \\
\hline 34 & 2 & - \\
\hline 35 & 2 & + \\
\hline 36 & 2 & + \\
\hline 37 & 2 & + \\
\hline 38 & 2 & + \\
\hline 39 & 2 & + \\
\hline 40 & 2 & - \\
\hline 41 & 2 & + \\
\hline 42 & 2 & + \\
\hline 43 & 2 & - \\
\hline
\end{tabular}

Multi-variate logistic regression analysis showed that high tumor stage and metastasis are positively related to the success of the engraftment.

The future goal is to use the new method of patient-tumor transplantation to enable universal individualized therapy for cancer patients, such that each cancer patient has their own mouse tumor model to help identify improved therapy. The results of the present study show that high tumor stage and the presence of metastasis in the patient increased the probability of tumor engraftment in nude mice, suggesting that the patients in greatest need will have the best chance for identification of more effective therapy with a mouse model of their tumor, especially the PDOX model, which mimics the patient (4, 12-16).

\section{Conclusion}

Patient-tumor engraftment is significantly increased by cotransplanting tumors and surrounding tissue in nude mice, which gives rise to the possibility of wide-spread use of individualized mouse tumor models for patients, enabling screening for effective drugs for each patient. With the use of highly-immunodeficient mice, such as NOG (18), establishment rates of patient tumors approaching $100 \%$ can be expected with the new method of the present report.

\section{Conflicts of Interest}

The Authors declare no conflicts of interest.

\section{Authors' Contributions}

Takuya Murata provided the surgical specimens and wrote the first draft of the manuscript. Chihiro Hozumi invented the new cotransplantation method and co-implanted the patient tumors with surrounding tissue in nude mice. Yukihiko Hiroshima implanted some tumors in nude mouse using the standard transplantation method. Koichiro Shimoya, Atsushi Hongo, Sachiko Inubushi and Hirokazu Tanino provided scientific advice for the project. Robert M. Hoffman supervised the study and revised the manuscript.

\section{Acknowledgements}

This study was supported, in part, by a Research Project Grant R01B077 from Kawasaki Medical School. This paper is dedicated to the memory of AR Moossa MD, Sun Lee MD, Professor Li Jiaxi and Masaki Kitajima, MD.

\section{References}

1 Longo DL: Tumor heterogeneity and personalized medicine. N Eng1 J Med 366(10): 956-957, 2012. PMID: 22397658. DOI: 10.1056/NEJMe1200656

2 Gerlinger M, Rowan AJ, Horswell S, Math M, Larkin J, Endesfelder D, Gronroos E, Martinez P, Matthews N, Stewart A, Tarpey P, Varela I, Phillimore B, Begum S, McDonald NQ, Butler A, Jones D, Raine K, Latimer C, Santos CR, Nohadani M, Eklund AC, Spencer-Dene B, Clark G, Pickering L, Stamp G, Gore M, Szallasi Z, Downward J, Futreal PA and Swanton C: Intratumor heterogeneity and branched evolution revealed by multiregion sequencing. N Engl J Med 366(10): 883-892. PMID: 22397650. DOI: 10.1056/NEJMoa1113205

3 Rygaard J and Povlsen CO: Heterotransplantation of a human malignant tumour to "Nude" mice. Acta Pathol Microbiol Scand 
77(4): 758-760, 1969. PMID: 5383844. DOI: 10.1111/j.16990463.1969.tb04520.x

4 Patient-Derived Mouse Models of Cancer. Patient-Derived Orthotopic Xenografts (PDOX). Hoffman RM (eds.). New York, Humana Press, 2017. DOI: 10.1007/978-3-319-57424-0

5 Hyman DM, Taylor BS and Baselga J: Implementing genomedriven oncology. Cell 168(4): 584-599, 2017. PMID: 28187282. DOI: $10.1016 /$ j.cell.2016.12.015

6 Vescio RA, Redfern CH, Nelson TJ, Ugoretz S, Stern PH and Hoffman RM: In vivo-like drug responses of human tumors growing in three-dimensional gel-supported primary culture. Proc Natl Acad Sci 84(14): 5029-5033, 1987. PMID: 3474637. DOI: $10.1073 /$ pnas.84.14.5029

7 Furukawa T, Kubota T, Hoffman RM. Clinical applications of the histoculture drug response assay. Clin Cancer Res 1(3): 305311, 1995. PMID: 9815986.

8 Hoffman RM and Vescio RA: Development of the histoculture drug response assay (HDRA). Methods Mol Biol 1760: 39-48, 2018. PMID: 29572792. DOI: 10.1007/978-1-4939-7745-1_5

9 Jun E, Park Y, Lee W, Kwon J, Lee S, Kim MB, Lee JS, Song KB, Hwang DW, Lee JH, Hoffman RM and Kim SC: The identification of candidate effective combination regimens for pancreatic cancer using the histoculture drug response assay. Sci Rep 10(1): 12004, 2020. PMID: 32686712. DOI: 10.1038/ s41598-020-68703-x

10 Tuveson D and Clevers H: Cancer modeling meets human organoid technology. Science 364(6444): 952-955, 2019. PMID: 31171691. DOI: $10.1126 /$ science.aaw6985

11 Drost J and Clevers H: Organoids in cancer research. Nat Rev Cancer 18(7): 407-418, 2018. PMID: 29692415. DOI: 10.1038/ s41568-018-0007-6

$12 \mathrm{Fu}$ XY, Besterman JM, Monosov A and Hoffman RM: Models of human metastatic colon cancer in nude mice orthotopically constructed by using histologically intact patient specimens. Proc Natl Acad Sci 88(20): 9345-9349, 1991. PMID: 1924398. DOI: $10.1073 /$ pnas.88.20.9345

13 Murakami T, Murata T, Kawaguchi K, Kiyuna T, Igarashi K, Hwang HK, Hiroshima Y, Hozumi C, Komatsu S, Kikuchi T, Lwin TM, Delong JC, Miyake K, Zhang Y, Tanaka K, Bouvet M, Endo I and Hoffman RM: Cervical cancer patient-derived orthotopic xenograft (PDOX) is sensitive to cisplatinum and resistant to nab-paclitaxel. Anticancer Res 37(1): 61-65, 2017. PMID: 28011474. DOI: 10.21873/anticanres.11289
14 Yamamoto J, Murata T, Tashiro Y, Higuchi T, Sugisawa N, Nishino H, Inubushi S, Sun YU, Lim H, Miyake K, Hongo A, Nomura T, Saitoh W, Moriya T, Tanino H, Hozumi C, Bouvet M, Singh SR, Endo I and Hoffman RM: A triple-negative matrix-producing breast carcinoma patient-derived orthotopic xenograft (PDOX) mouse model is sensitive to bevacizumab and vinorelbine, regressed by eribulin and resistant to olaparib. Anticancer Res 40(5): 2509-2514, 2020. PMID: 32366395 DOI: 10.21873/anticanres. 14221

15 Igarashi K, Kawaguchi K, Murakami T, Miyake K, Kiyuna T, Miyake M, Hiroshima Y, Higuchi T, Oshiro H, Nelson SD, Dry SM, Li Y, Yamamoto N, Hayashi K, Kimura H, Miwa S, Singh SR, Tsuchiya H and Hoffman RM: Patient-derived orthotopic xenograft models of sarcoma. Cancer Lett 469: 332-339, 2020. PMID: 31639427. DOI: 10.1016/j.canlet.2019.10.028

16 Hoffman RM: Patient-derived orthotopic xenografts: better mimic of metastasis than subcutaneous xenografts. Nat Rev Cancer 15(8): 451-452, 2015. PMID: 26422835. DOI: $10.1038 / \mathrm{nrc} 3972$

17 Peterson JF, Roden DM, Orlando LA, Ramirez AH, Mensah GA and Williams MS: Building evidence and measuring clinical outcomes for genomic medicine. Lancet 394(10198): 604-610, 2019. PMID: 31395443. DOI: 10.1016/S0140-6736(19)31278-4

18 Ito M, Hiramatsu H, Kobayashi K, Suzue K, Kawahata M, Hioki K, Ueyama Y, Koyanagi Y, Sugamura K, Tsuji K, Heike T and Nakahata T: NOD/SCID/gamma(c)(null) mouse: an excellent recipient mouse model for engraftment of human cells. Blood 100(9): 3175-82, 2002. PMID: 12384415. DOI: 10.1182/blood2001-12-0207
Received August 23, 2020

Revised September 16, 2020 Accepted September 17, 2020 